Review

\title{
Moving towards the Future of Radio-Immunotherapy: Could We "Tailor" the Abscopal Effect on Head and Neck Cancer Patients?
}

\author{
Marco De Felice ${ }^{1,2, *} \mathbb{C}$, Mariagrazia Tammaro ${ }^{3}$, Davide Leopardo ${ }^{2}$, Giovanni Pietro Ianniello ${ }^{2}$ \\ and Giacinto Turitto ${ }^{2}$ \\ 1 Department of Precision Medicine, University of Campania "Luigi Vanvitelli", 80138 Naples, Italy \\ 2 Division of Oncology, AORN “Sant' Anna e San Sebastiano", 81100 Caserta, Italy; davleo@inwind.it (D.L.); \\ ianniellog@libero.it (G.P.I.); turittodino@libero.it (G.T.) \\ 3 Division of Hematology, AOU “Federico II”, 80131 Naples, Italy; mariagrazia.tammaro96@gmail.com \\ * Correspondence: marco.defelice@studenti.unicampania.it
}

Citation: De Felice, M.; Tammaro, M Leopardo, D.; Ianniello, G.P.; Turitto, G. Moving towards the Future of Radio-Immunotherapy: Could We "Tailor" the Abscopal Effect on Head and Neck Cancer Patients? Immuno 2021, 1, 410-423. https://doi.org/ 10.3390/immuno1040029

Academic Editor: Toshihiko Torigoe

Received: 23 September 2021

Accepted: 3 November 2021

Published: 5 November 2021

Publisher's Note: MDPI stays neutral with regard to jurisdictional claims in published maps and institutional affiliations.

\begin{abstract}
The abscopal effect $(\mathrm{AbE})$ is defined as radiation-induced shrinkage of distant, non-treated, neoplastic lesions and it is considered the best clinical picture of the efficient immune stimulation by irradiation. The first report about abscopal tumor regression upon radiotherapy dates back to the beginning of the 20th century. The growing preclinical and clinical synergism between radiation and immunotherapy gave birth the purpose to more easily reproduce the abscopal effect, nevertheless, it is still rare in clinical practice. In this review we summarize immunological modulation of radiotherapy, focusing on the well-balanced equilibrium of tumor microenvironment and how radioimmunotherapy combinations can perturb it, with particular attention on head and neck squamous cell cancer. Finally, we investigate future perspectives, with the aim to "tailor" the abscopal effect to the patient.
\end{abstract}

Keywords: abscopal effect; HNSCC; precision medicine; immunotherapy; radiotherapy

\section{Introduction}

Head and neck squamous cell cancer (HNSCC) is the sixth most common cancer worldwide, more than $90 \%$ involving oral cavity, pharynx, or larynx. Known risk factors are excessive use of tobacco and alcohol, acquiring infection with human papilloma virus, especially HPV 16, HPV 18, and Epstein-Barr virus [1]. Radiotherapy represents a cornerstone in its management, and it is clinically implemented in different regimens; for locally advanced disease, modulated intensity radiotherapy (IMRT) is classically used, with daily doses ranging from 1.8 to $2.0 \mathrm{~Gy}$, either alone or in combination with concomitant chemotherapy or cetuximab [2,3]. In recurrent or metastatic disease, the standard first line is platinum-based chemotherapy with 5-fluorouracil and cetuximab [4], however, stereotactic body radiotherapy (SBRT) with fractionation between 8 and 15 Gy is widely used [5]; in fact, thanks to its high spatial precision it could achieve a better control of local symptoms reducing toxicities. Its growing use increased reports of the abscopal effect as a systemic distant response of non-irradiated tumors or metastasis, as a consequence of proinflammatory changes in tumor microenvironment (TME) against cancer antigens [6,7]. A further boost has been given by the introduction of the immunotherapy targeting Cytotoxic T-Lymphocyte Antigen 4 (CTLA-4) and Programmed Death-Ligand 1 (PD-L1)/PD-1 axis: RT stimulates a robust tumor antigen cross-presentation in nodes while CTLA-4 blockade enhanced the priming of responsive T-cells in TME, highlighting an interesting clinical synergism. [8,9]. The goal of radioimmunotherapy should be to stimulate but also improve the duration of the immune response. Among various combination strategies, SBRT is most effective in inducing the abscopal effect, although the right dose and ideal fractionation has yet to be identified [9]. 


\section{Insight into the Abscopal Effect: Modulation of the Tumor Microenvironment (TME) by Irradiation}

Beneficial consequences of the abscopal effect have been known for many years, understood as a reduction in the development of metastases in patients treated with radiotherapy on the primary tumor [8]. The starting point is the stimulation of the immune response and the anti-neoplastic transition of the TME induced by radiation treatment, however, nowadays it is not known what the best radiotherapy strategy for this purpose is [9]. In fact, current preclinical evidence could be very conflicting, testifying to the difficulty in the reproducibility of the phenomenon [6,9]. Ionizing radiation damages DNA in target cells, causing DNA-DNA crosslinks, DNA-protein crosslinks, modification of the deoxyribose rings and bases, and induces release of cytokines and chemokines involved in the alteration of the tumor stromal microenvironment [10]. Radiotherapy can modify the TME from immunosuppressive or "cold" to immunostimulatory or "hot", even though the reverse phenomenon has also been observed. The relationship between TME and radiotherapy is extremely complex, and it can be compared to a well balanced scale [11-15]. Typical aspects of a "cold" TME are a high number of regulatory T (T-reg) cells and myeloidderived suppressive cells (MDSCs), poor T-Helper 1 (T-h1), Natural Killer (NK), and CD8+ cells, few functional antigen-presenting cells (APC) and production of immunosuppressive cytokines, while "hot" TME is rich in Th1-type chemokines, NK and CD8+ lymphocytes, high PD-L1 expression, and APCs (Figure 1). The creation of an immunosuppressive TME reflects one of the hallmarks of cancer, the immune escape. Macrophages infiltrating the TME should be differentiated in two phenotypes, M1 and M2: M1 macrophages are pro-inflammatory and secrete interleukin-12 (IL-12) and Tumor Necrosis Factor $\alpha$ (TNF- $\alpha$ ), that may act killing tumor cells; on the other hand, M2 macrophages work as antiimmunogenic cells, expressing anti-inflammatory cytokines such as interleukin-10 (IL-10) and Transforming Growth Factor- $\beta$ (TGF-B), which subsequently inhibit the function of effector T-cells and favor tumor progression $[16,17]$.

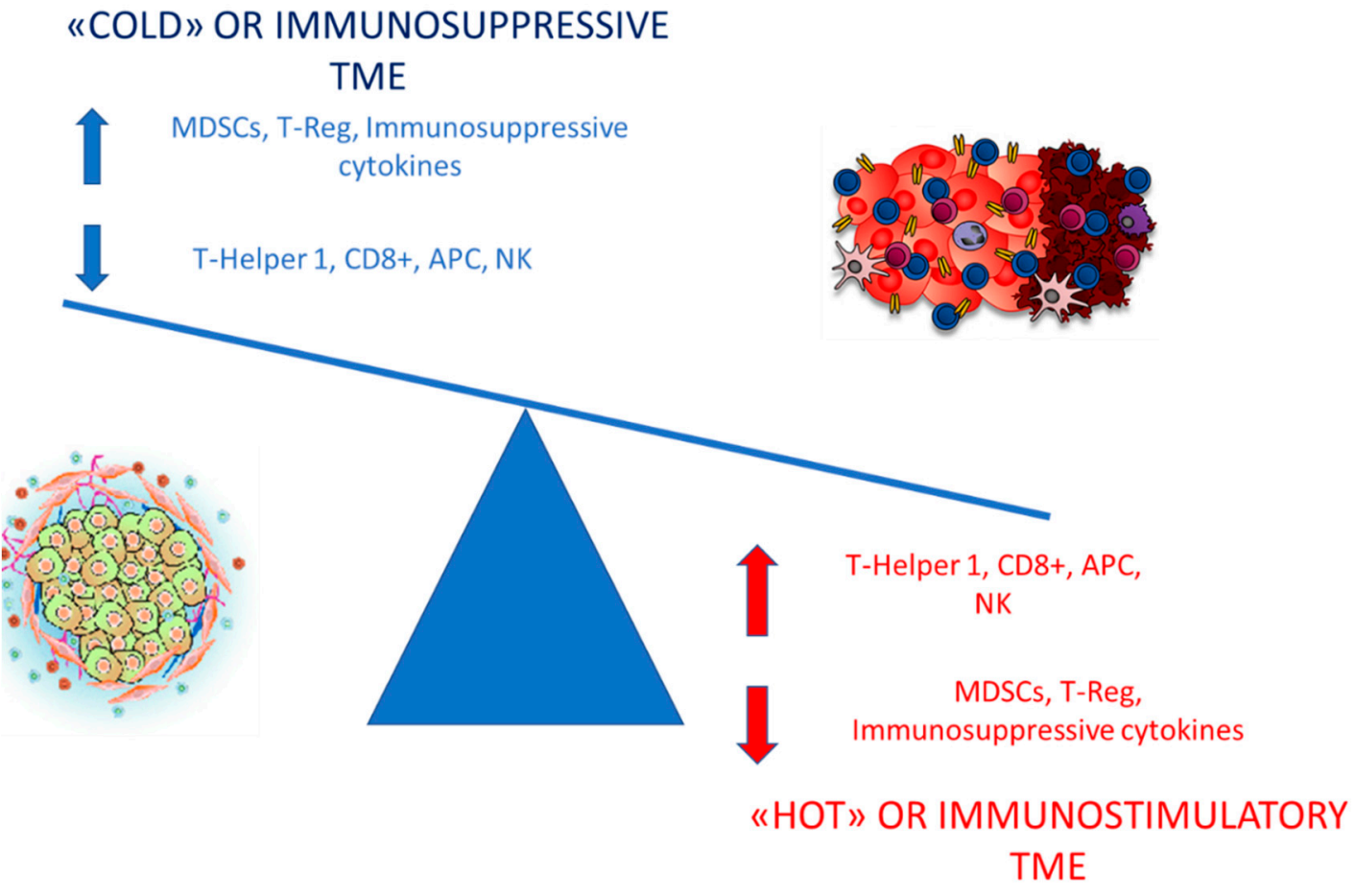

Figure 1. Differences between "cold" and "hot" TME.

Anti-inflammatory M2 macrophages polarize cold TME and antagonize the immune response induced by radiation [18]. Ideally, associations between chemotherapy, im- 
munotherapy, and radiotherapy should shift the balance, promoting pro-immunogenic effects and mitigating immunosuppressive features. The immune response induced by radiation treatment is extremely articulated and is carried out by cytokines and chemokines with contrasting functions: IL-6, IL-10, and Colony Stimulating Factor-1 (CSF-1) have a pro-tumorigenic profile, stimulating the proliferation and growth of neoplastic cells [19]; Chemokine-Receptor-Type (CXCR)-4 ligand mediated chemotaxis of pro-tumorigenic CD11b + myeloid-derived cells and modulate organ-specific metastasis of solid tumors, whereas CXCL9, CXCL10, and CXCL16 block tumor growth and boost antitumor immunity via effector T-cells [20-22].

Damage-associated molecular patterns (DAMPs), such as the non-histone chromatinbinding protein high-mobility group 1 (HMG-1) and mitochondrial DNA (mtDNA), are endogenous danger signal molecules, normally invisible to the immune system, released to the extracellular space from damaged or dying cells due to irradiation [23]. Once DAMPs are released from the cell into the TME, they promote an innate immune inflammatory response by binding to a pattern-recognition receptor, in particular Toll-Like Receptors (TLRs) [23]. This potently immunostimulatory mechanism is named immunogenic cell death [24,25]. DAMPs enable the recruitment and activation of Basic Leucine Zipper ATFLike Transcription Factor 3 (BATF3)-dependent dendritic cells, critical for tumor-specific cross-priming of CD8+ T-cell memory [23]. BATF3-driven DC might also contribute in recruiting circulating cytotoxic $\mathrm{T}$ lymphocytes as well as in activating tumor-resident CD8+ T-cells, under tonic inhibition by PD-1 and TGF $\beta 1$ signaling.

TGF $\beta 1$ has a key role in preserving a cold TME by promoting regulatory T-cell differentiation, reducing CD8+ cytotoxicity, suppressing CD4+ T-cell differentiation, and blocking NK-cell proliferation [26]. It is rapidly stimulated by radiation across a wide range of RT doses $[19,27]$. Radiation-damaged cancer cells release cancer-specific peptides, processed by DC and presented to T-cells, and enhance the pro-phagocytosis signal, the calreticulin, that mediates macrophages and dendritic cells, stimulating the presentation of antigens and the priming of T-cells $[28,29]$. In addition, RT-damaged DNA is released from the nucleus into the cytoplasm, activating the cGAS-STING (Stimulator of Interferon Genes) transduction cascade, which stimulates IFN $\gamma$ transcription. This cytokine upregulates the class I MHC on APC, such as macrophages and dendritic cells, which interact with tumor neoantigens in nodes, where they mainly activate CD8+ T lymphocytes. As a result, effector T-cells primed in lymph nodes migrate both in the primitive tumor and in the un-irradiated metastases to exert their cytocide effect [30-33]. Such a robust response can not only drive the eradication of radioresistant cancer cells in the irradiated lesions, but also potentially attack non-irradiated metastases, commonly referred to the abscopal response [27,28]. Further evidence about the immunological nature of this mechanism are that abscopal responses could be abolished in preclinical murine models lacking CD8+ T-cells, as well as in mice in which type I IFN signaling is inhibited [34].

\section{Radiotherapy and Immune-Checkpoint Inhibitors (ICIs): Potentially a Well Balanced Synergism}

Radiotherapy immunogenicity is strictly related to tumor-specific characteristics, such as heterogeneity and radiosensitivity, and specific RT aspects like dose, fractionation, and timing of administration. Most of the clinical data regarding the use of radioimmunotherapy combinations are limited to either anti-CTLA-4 or anti-PD-1 agents: RT stimulates antigen cross-presentation and T-cell priming in draining nodes while CTLA-4 inhibitors enhance priming phase of effector T-cell activation induced by RT, leading to proimmunogenic infiltrate of the TME. Blocking CTLA-4 enhances T-cell activation, increasing the CD8+/T-reg ratio, and strengthening the in situ vaccination effect [35-39].

PD-1 is expressed on T-cells, DCs, and NK cells: PD-1/PD-L1 pathway primarily inhibits T-cell proliferation by blocking cell-cycle progression, thus protecting tumor cells from T-cell attack. A recent study suggested that radiation-induced double-strand breakage of DNA results in upregulation of the expression of PD-L1 thanks to Ataxia-telangiectasiamutated (ATM) and ataxia telangiectasia and Rad3-related (ATR) kinases [40-43]. Therefore, 
PD-L1 hyperexpression on cancer cells could be associated with a higher rate of responses to specific inhibitors while radiotherapy could act as a "Trojan horse" [42,43].

An excellent murine model published by Twyman-Saint Victor et al. clarified that radiotherapy and anti-CTLA4 monoclonal antibodies (mAbs) led to upregulation of PD-L1 on melanoma cells, mediating T-cell exhaustion and explaining at least in part the limited local and abscopal responses observed [44]. Anti-CTLA4 predominantly inhibits T-reg cells, thereby increasing CD8/T-reg ratio while radiation enhances the diversity of T-cell receptor (TCR) repertoire of intratumoral T-cells [44]. Addition of PD-L1 inhibitor reverses T-cell exhaustion, mitigates depression in the CD8/Treg ratio, and further encourages oligoclonal T-cell expansion [44]. Similarly to results from mice, patients with melanoma showing high PD-L1 levels on neoplastic cells did not respond to radiotherapy plus anti-CTLA4 $\mathrm{mAb}$, demonstrated persistent T-cell exhaustion and rapidly progressive disease.

Evidence regarding the optimal timing, dose, schedules, sequences, and fractionation of radiotherapy are conflicting. Pre-clinical studies highlighted that starting anti-PDL1 treatment 7 days following RT was inferior to starting on either the first or the last day [45]; however, some data also show how radiotherapy-anti PD-L1 sequence, with late administration of the checkpoint inhibitor, reinvigorates exhausted T-cells while an early sequence favors the differentiation and initial activation of T-cells [46,47]. Nowadays, it is clear that there is a synergism between immunotherapy and RT either as a single-fraction or in fractionated courses. Following irradiation with 12 Gy on 2 consecutive days, overall leukocyte and CD8+ T-cell frequencies peak at 5 days post-RT and then gradually decline to pre-RT levels [48]. Five days post-RT also reflects the highest CD8/T-Reg ratio, probably the ideal time-point for checkpoint blockade. Moreover, Frey et al. showed that after irradiation of $5 \mathrm{~Gy} \times 2$ fractions, CD8+ peak at day 8 and then decline while T-regs have a bimodal peak on days 8 and 10 [49]. Knowing the kinetics of infiltration of immune cells should be correlated with the time of administration of the ICIs, in order to achieve the maximum immunostimulant effect.

Hypofractionated radiotherapy (hRT) is the delivery of fewer, larger ( $>2 \mathrm{~Gy}$ ) doses of radiotherapy and is a potential strategy for improving dose intensity. hRT appears particularly immunogenic: T lymphocytes, including Tumor-infiltrating lymphocytes (TILs), have generally been considered as highly radiosensitive [50,51], that is why it could be postulated that extending hRT schedules might be less immunogenic if administered in the period in which T lymphocytes, stimulated by RT/ICI combination, migrate to TME [50,51]. Following the experience of Frey [49], Zhang et al. compared a combination of anti-PD1 treatment and hRT with different schedules and equivalent biologically effective doses in mice affected by melanoma. Anti-PD1 antibody was given weekly while primary tumor was irradiated with $3 \times 9.18$ Gy in 3 or 5 days or with $5 \times 6.43$ Gy in 10 days [52]. All the combinations inhibited growth of irradiated primary and non-irradiated secondary tumors greater than $\mathrm{hRT}$ and anti-PD1 monotherapy; similarly, local and systemic tumor-specific CD8+ T-cell responses and TILs were also similar across short or extended hRT schedules [52]. Zhang's experience also highlighted how regional and abscopal antineoplastic biological effects of the extended schedules are similar to the shorter ones only if the regional lymph nodes provide sufficient cancer-specific T-cells in the TME [52].

Historically, HNSCC was considered poorly responsive to high-dose hRT rather than low-dose hRT, however, low-dose schedules may induce lymphopenia and immunosuppression [53]. Morisada et al. analyzed immune correlates, primary tumor, and abscopal control rates as a result of two different radio-immunotherapy combinations of PD-1 monoclonal antibody with either daily low-dose fractionated radiotherapy (LDRT, $2 \mathrm{~Gy} \times 10$ ) or high-dose hypofractionated treatment $(8 \mathrm{~Gy} \times 2)$ in syngeneic mice. High-dose hRT did not affect peripheral and tumor-infiltrating CD8+ T-cells, reduced neoplastic accumulation of granulocyte-like myeloid suppressor cells, while T-reg lymphocytes were largely unaltered. Expression of IFN-responsive MHC class I peptides and PD-L1 were enhanced in tumors treated with $8 \mathrm{~Gy} \times 2$ compared to $2 \mathrm{~Gy} \times 10$ schedule. Functionally, tumor-specific CD8 ${ }^{+}$lymphocytes responses within tumor draining lymph nodes were enhanced following $8 \mathrm{~Gy}$ 
$\times 2$ schedule but suppressed following $2 \mathrm{~Gy} \times 10$ irradiation [53]. When combined with PD-1 mAb, reversal of adaptive immune resistance was observed following $8 \mathrm{~Gy} \times 2$, but not following $2 \mathrm{~Gy} \times 10$, with subsequent enhancement of CD8+ cell-dependent primary and abscopal tumor response. These data strongly support that high-dose hRT preserves or enhances anti-tumor immunity compared to daily low-dose fractionated irradiation and, when combined with PD-1 inhibitor, reverses adaptive immune resistance, promotes anti-tumor immunity, and controls primary and distant lesions [53].

In order to determine the optimal dose for tumor and immunological response, Schaue et al. conducted a single fraction dose escalation study with doses ranging from 5 to $15 \mathrm{~Gy}$ and demonstrated that fractions of $7.5 \mathrm{~Gy}$ and above are immune-stimulatory, determining an increased number of tumor-reactive T-cells [54]. Instead a dose higher than $15 \mathrm{~Gy}$ in single fraction increased splenic T-reg fraction, while the same total dose fractionated boosted the number of effector T-cells in the spleen and decreased T-regs, with an optimal dose fractionation of $7.5 \mathrm{~Gy} \times 2$ [54]. Dewan et al. investigated three different regimens of radiotherapy $(20 \mathrm{~Gy} \times 1,8 \mathrm{~Gy} \times 3$, or $6 \mathrm{~Gy} \times 5)$ to obtain abscopal response in syngeneic mice models, with or without antiCTLA-4, finding that a significant AbE was only induced when RT was administered in fractionated schedules [55]. Additionally, observations by Vanpouille-Box, et al. suggest that AbE could only be achieved with hRT $(8 \mathrm{~Gy} \times 3)$ when combined with immune checkpoint inhibitors [32,33].

The systemic antitumor response of focal hRT combined with ICI may also be mitigated by the immunosuppressive properties of the non-irradiated distant tumors, that hinder T-cell entry and T-cell functioning [56,57]. In this regard, strategies that attempt to modulate the stroma of metastasis to improve T-cell infiltration are basic to invigorate the systemic antitumor response of combined hRT and immune checkpoint inhibitors. In fact, despite its very poor tumor-killing effect, LDRT is effective to T-cell recruitment $[58,59]$. Klug et al. have shown that LDRT (with one fraction of $2 \mathrm{~Gy}$ ) may reprogram macrophages in TME, leading to the production of inducible nitric oxide synthase (iNOS), which normalizes tumor vasculature, thus promoting T-cell infiltration and enhancing the efficacy of adoptive T-cell therapy [58]. Moreover Yin et al. preclinically demonstrate that LDRT on established metastases, in combination with ICIs, significantly enhances the abscopal response to hRT treatment on the primary tumor compared to hRT/anti-PD1, hRT/LDRT, or LDRT/anti-PD1 combined treatments [60]. The enhanced abscopal effect was linked to an increased infiltration of CD8+ effector T-cells and an upregulated expression of T-cellattracting chemokines, so localized LDRT to a second lesion should be indispensable for an enhanced systemic antitumor response, triggered by combined focal hRT and anti-PD1 therapy [60].

This preclinical model has been later confirmed by a post-hoc analysis of a 3 immunoradiation trial by Menon et al. in which patients, that received LDRT (1-20 Gy), either as scatter from high-dose radiation or from intentional treatment of a second isocenter with low-dose radiation, in association with high-dose radiation and immunotherapy, were evaluated for response [61]. The LDRT lesions were compared to those that received no radiation ( $<1$ Gy total). They assessed that LDRT may increase systemic response rates of metastatic disease treated with high-dose radiation and ICI combinations, offering a clinical proof-of-principle of the ability of LDRT to polarize tumor macrophage in M1 subtype and shift TME from "cold" to "hot" [61,62].

Summarizing, although CD8+ T lymphocytes are present between neoplastic cells, they could be exhausted and could not recognize cancer cells that they were primed to because of an immune-suppressive TME. An ideal radiation dose and fractionation may induce immunogenic cancer cell death and activate anti-tumor T-cell response via APC maturation. Radiation doses $>12$ Gy per fraction may attenuate immunogenicity while hypofractionated regimens (i.e., $8 \mathrm{~Gy} \times 3$ ) should be more effective in combination with ICIs for better local response rate and abscopal effect [32]. 


\section{The Abscopal Effect in Clinical Practice: What about HNSCC?}

The abscopal effect is a rare phenomenon predominantly described in highly immunogenic tumors like renal cell cancer, melanoma, and hepatocellular carcinoma. In their proof of principle trial, Golden et al. demonstrated objective abscopal responses in 11 patients with metastatic tumors, mainly breast and non-small cell lung cancer (NSCLC), treated with a combination of local radiotherapy with granulocyte-macrophage colony stimulating factor (G-CSF), as a prototype of immunotherapy [62]. Trommer et al. retrospectively collected metastatic patients, treated simultaneously with pembrolizumab or nivolumab and radiotherapy, with at least one lesion not locally targeted; they described $\mathrm{AbE}$ in seven patients between melanoma, NSCLC, and renal cell cancer [63]. In the PEMBRO-RT trial, Theelen et al. investigated objective response rate and progression free survival about the sequence SABR 8 Gy $\times$ 3-pembrolizumab versus pembrolizumab alone in the metastatic setting. SABR was administered 7 days before ICI. ORR and median PFS were significantly increased in SABR-pembrolizumab group, respectively, $36 \%$ vs. $18 \%$ and 6.6 months vs. 1.9 months [64]. Moreover, secondary analysis of KEYNOTE-001 also revealed that RTpembrolizumab sequence showed longer progression free survival versus pembrolizumab alone in advanced NSCLC; however, the correct sequence is still far from being established considering that previous systematic analyses suggest that ICI-RT may be associated with superior outcomes [65].

The RT-induced abscopal effect is anecdotal for HNSCC. Definitive radiotherapy for stage III or IV HNSCC was delivered in 1.8-2 Gy in 35 daily fractions, with a median whole dose of $70 \mathrm{~Gy}$, and simultaneous chemotherapy, mostly cisplatin (with or without 5-Fluorouracil). Palliative RT ranges in 20-30 Gy in five fractions even though different regimens have been established. A split course of two cycles of $25 \mathrm{~Gy}$ in 10 fractions was introduced by Stevens et al., with total dose of $50 \mathrm{~Gy}$, leading to tumor response in $82 \%$ of patients [66]. The "QUAD SHOT regimen", that consisted of $3.7 \mathrm{~Gy}$ in four fractions given twice a day for 2 consecutive days in order to achieve a total of $44.4 \mathrm{~Gy}$ in 12 fractions, impacted positively on clinical outcomes, overall tumor response rate, and symptom relief in $50-70 \%$ of patients, with minimal toxicity [67]. Moreover Agarwal et al. proposed a dose-intensive palliative RT regimen of 40 Gy in 16 fractions, obtaining a treatment response rate and symptom relief of about $75 \%$; therefore, as a palliative treatment, a higher dose of hRT may be proposed with positive outcomes [68].

Clinical data evaluating ICI-RT combination other than metastatic melanoma or NSCLC are mostly limited to case reports, especially for head and neck squamous cell cancer (Table 1). Interestingly Menon post-hoc analysis did not collect immune-irradiation abscopal responses in HNSCC patients. This result seems in part due to its genetics [61]: molecularly HNSCC, particularly HPV-, is considered a "loss of function" cancer, and inactivating mutations of TP53 and CDKN2A dominate the genetic landscape [69]. This may affect the mode of RT-induced cell death, as well as its immunogenicity. In fact, the best abscopal responses upon RT have always been achieved with "gain of function" cancer models driven by activating mutations in RAS, such as melanoma, and there seems to be a link between RAS status and PD-L1 expression [70,71]. 
Table 1. Case reports about the abscopal effect in HNSCC.

\begin{tabular}{|c|c|c|}
\hline Authors & Diagnosis & Treatment-Induced Abscopal Effect \\
\hline Ellerin et al. [72] & $\begin{array}{c}\text { Poorly differentiated non-small cell carcinoma } \\
\text { of the right parotid as metastatic pulmonary } \\
\text { disease }\end{array}$ & Palliative radiotherapy to the primary site \\
\hline Forner et al. [73] & $\begin{array}{c}\text { Advanced sinonasal squamous cell carcinoma } \\
\text { with lung metastases }\end{array}$ & $\begin{array}{l}\text { Nivolumab with palliative radiotherapy to single } \\
\text { lung metastasis }\end{array}$ \\
\hline Mazzaschi et al. [74] & $\begin{array}{c}\text { Hypopharyngeal carcinoma with a single bone } \\
\text { metastasis }\end{array}$ & Definitive chemoradiotherapy on the primary site \\
\hline Choi et al. [75] & $\begin{array}{l}\text { Cutaneous squamous cell carcinoma and } \\
\text { larynx tumor }\end{array}$ & Immunotherapy plus stereotactic radiotherapy \\
\hline Shinde et al. [76] & $\begin{array}{c}\text { Squamous cell carcinoma of the hypopharynx } \\
\text { and oropharynx }\end{array}$ & $\begin{array}{l}\text { Nivolumab plus ipilimumab plus Quad Shot } \\
\text { radiotherapy }\end{array}$ \\
\hline
\end{tabular}

Nevertheless, Ellerin et al. reported that an 84-year-old woman, affected by stage IV poorly differentiated non-small cell carcinoma of the right parotid and lung metastases, underwent only palliative radiotherapy to the primary site, with no chemotherapy or immunotherapy: parotid cancer regressed while several non-irradiated lung lesions completely resolved [72]. Forner et al. presented a case of a man that underwent craniofacial resection and adjuvant chemoradiotherapy for advanced sinonasal squamous cell carcinoma, and rapidly progressed with lung metastases. Nivolumab was initiated, even with oligometastatic progression as the best response. Integrating palliative radiotherapy to single metastasis, the abscopal effect was observed with all distant sites of metastatic disease shrinking [73]. Mazzaschi et al. described a case of a hypopharyngeal carcinoma with a single bone metastasis, treated with definitive chemoradiotherapy omitting local treatment of the bone lesion, who remained relapse-free for 6 years [74]. Choi et al. presented two patients with recurrent metastatic head and neck squamous cell carcinoma, a cutaneous squamous cell carcinoma, and a larynx tumor, that developed a complete response via the abscopal effect following combined immunotherapy and SBRT, the former with a total of $45 \mathrm{~Gy}$ in five fractions, the latter with a total of $21 \mathrm{~Gy}$ in three fractions of $7 \mathrm{~Gy}$ [75]. The abscopal effect in HNSCC could be triggered even in the case of immune-resistance progressive disease too. Shinde et al. reported a patient affected by squamous cell carcinoma of the left hypopharynx and oropharynx with bulky left-neck lymphadenopathy, with local and lung progression after ipilimumab and nivolumab, infused concurrently every three weeks for four cycles. Palliative QUAD SHOT regimen was given with $3.7 \mathrm{~Gy}$ BID for 2 days to the pharynx and 3.3 Gy BID for 2 days to the microscopic areas at high risk of disease, continuing nivolumab plus ipilimumab beyond progression. RT was not administered to the lung. Fourteen days after irradiation, left-neck adenopathy decreased, but lung metastases too. QUAD SHOT RT was repeated twice at one-month intervals, with excellent response and tolerability [76]. Notably, QUAD SHOT regimen without immune-checkpoint inhibitors did not lead to the abscopal effect [77].

In a phase I/II trial, Bahig et al. assessed the safety and efficacy of triple treatment combination (TTC), durvalumab plus tremelimumab plus SBRT (up to 15 Gy per fraction for 2-5 metastases), in metastatic HNSCC. No evidence of AbE was shown, however, a positive trend of overall survival (OS) and progression-free survival (PFS) was demonstrated, maybe thanks to a synergism between local SBRT and ICIs [78]. Ongoing trials could provide assistance for future observations about the abscopal effect in radio-immunotherapy combinations (Table 2): proton SBRT with PD-1 blockade immunotherapy in both the locoregionally recurrent and metastatic settings (ClinicalTrials.gov Identifier: NCT03539198); radiotherapy with concurrent and adjuvant Pembrolizumab versus concurrent chemotherapy in patients with advanced/intermediate-risk p16+ head and neck squamous cell carcinoma (ClinicalTrials.gov Identifier: NCT03383094). 
Table 2. Ongoing trials about radioimmunotherapy combinations in HNSCC. SBRT, stereotactic body radiotherapy; RT, radiotherapy; HNSCC, head and neck squamous cell cancer; SCC, squamous cell cancer.

\begin{tabular}{|c|c|c|c|c|}
\hline Study & Phase & Interventional Arm & Patient Population & Status \\
\hline NCT03283605 & $\mathrm{I} / \mathrm{II}$ & $\begin{array}{c}\text { Durvalumab }+ \text { Tremelimumab }+ \\
\text { SBRT }\end{array}$ & Metastatic HNSCC & Recruiting \\
\hline NCT03383094 & II & Pembrolizumab + RT & $\begin{array}{l}\text { Intermediate/high-risk } \\
\text { p16-positive locoregionally } \\
\text { advanced HNSCC }\end{array}$ & Recruiting \\
\hline NCT03539198 & II & Nivolumab + Proton SBRT & $\begin{array}{c}\text { Recurrent/Progressive } \\
\text { Locoregional or Metastatic } \\
\text { HNSCC }\end{array}$ & Not recruiting \\
\hline NCT04454489 & II & $\begin{array}{c}\text { Pembrolizumab + QUAD SHOT } \\
\text { RT }\end{array}$ & $\begin{array}{c}\text { Advanced/Recurrent/Metastatic } \\
\text { HNSCC }\end{array}$ & Recruiting \\
\hline NCT02999087 & III & Cetuximab + Avelumab + RT & Locally Advanced HNSCC & Not recruiting \\
\hline NCT03426657 & II & $\begin{array}{c}\text { Durvalumab }+ \text { Tremelimumab }+ \\
\text { RT }\end{array}$ & Locally Advanced HNSCC & Not recruiting \\
\hline NCT03799445 & II & $\begin{array}{c}\text { Nivolumab + Ipilimumab + } \\
\text { IMRT }\end{array}$ & $\begin{array}{c}\text { Low-Intermediate Volume, } \\
\text { Local-Regionally Advanced } \\
\text { HPV-Positive Oropharyngeal SCC }\end{array}$ & Recruiting \\
\hline
\end{tabular}

\section{Future Perspectives: Tailored Treatment to Reach the Abscopal Effect}

Research to elucidate predictive factors of the abscopal effect should be focused on the model of patient-tailored treatment. Poleszczuk et al. generated a mathematical model that incorporates physiological information about T-cell trafficking to estimate the distribution of focal therapy activated-cells between metastatic lesions. They found that the dissemination of activated T-cells among multiple metastatic sites is intuitively predictable, even though they showed that not all metastatic sites participate in systemic immune surveillance equally. They considered how migration of T-cells and the initial imprinting mechanism by tumor antigen-presenting dendritic cells could be facilitated by the blood flow that physiologically sprays the affected organ, assessing that the success in triggering the abscopal effect depends, at least in part, on which metastatic site is selected for localized therapy. Collectively, their elegant work provided the framework to prospectively identify anatomically defined focal-therapy targets that should most likely trigger an immunemediated abscopal response and therefore may inform personalized treatment strategies in patients with metastatic disease [79].

Modern techniques such as volumetric modulated arc therapy (VMAT) induce larger volumes of healthy tissues receiving low doses of ionizing radiation, that could affect circulating lymphocytes and decrease the adaptive immune response [80]. In fact, lymphopenia measured post-RT may affect the occurrence of abscopal responses, influencing the prognosis of patients treated with RT and immunotherapy in HNSCC [81]. Therefore, the best volume of irradiation in patients receiving ICI may be different from who did not receive immunotherapy, in particular concerning the need to perform elective node irradiation. Irradiation in great vessels and draining lymph nodes (main location of T-cell cross-priming by DCs) could affect immune cell functions and migration [82]. Conventional radiotherapy schedules are generally formulated to deliver a full dose (50-70 Gy) to the tumor and prophylactic coverage to draining lymph nodes (45-50 Gy), as established by multiple clinical trials in various indications (e.g., HNSCC, cervical cancer, NSCLC) [83]. This approach might not be particularly appropriate when radiotherapy is delivered in doses and fractionations that support the activation of anti-cancer immunity, and even so less in the context of radioimmunotherapy. Although draining lymph nodes are not the only sites of T-cell cross-priming by dendritic cells, which can also occur in intratumoral tertiary lymphoid structures, they constitute the major site for the initiation of local and systemic anti-tumor immune responses; that is why it might be detrimental to perturb draining nodes with radiotherapy [84]. Patients with nasopharyngeal carcinoma with tumor-free draining nodes and treated with lymph node-sparing IMRT rarely exhibited locoregional 
relapse [85]. Similarly, clinical data on partial tumor irradiation sparing draining lymph nodes, combined with pembrolizumab, compare positively with previous results involving draining nodes irradiation [86].

Luke et al. reported results of a study that tested safety and feasibility of pembrolizumab and multisite SBRT in patients with metastatic solid tumors progressing on standard treatment. SBRT schedules varied by site: $15 \mathrm{~Gy} \times 3$ (45 Gy) for peripheral lung, liver and abdominal/pelvic; $10 \mathrm{~Gy} \times 5$ (50 Gy) for central lung and mediastinal/cervical; $10 \mathrm{~Gy} \times 3$ (30 Gy) for osseous and spinal/paraspinal. Pembrolizumab was infused within 7 days after SBRT. In order to quantify interferon- $\gamma$-induced gene expression, pre- and post-SBRT biopsy were analyzed: no significant changes have been reported from pre- to post-SBRT biopsy, however, post-SBRT IFN- $\gamma$-related immune score positively correlated to distant metastatic responses [86], with an abscopal response rate of $27 \%$ comparable to the analysis by Golden et al. [65]. Nevertheless, these results should be cautiously interpreted given that many patients in the trial were potentially sensitive to pembrolizumab alone [87].

Tumor radiosensitivity is often dose-related and associated with immune activation in solid tumors and in HNSCC too. First of all, Michna et al. identified specific networks of HNSCC clones radiosensitivity, with particular attention to senescence-associated secretory phenotype [88]; then, Reynders et al. developed the genomic-adjusted radiation dose (GARD), that provides the opportunity to adjust the dose of radiation to match the individual radiosensitivity of the tumor [89]; finally Strom et al. propose two distinct gene expression signatures (GES), the radiosensitivity index (RSI) and the 12-chemokine (CK) signature, to determine if radiosensitivity is associated with activation of the immune system [90]. RSI-low tumors had a significantly higher median 12-CK GES value compared with RSI-high tumors, indicating that radiosensitivity is associated with immune activation and radiosensitive tumors more frequently exhibit a phenotype of immune-activation. Combining these two signatures could be clinically useful to improve the identification of patients susceptible to the abscopal effect with integrated treatments, especially for non-oropharyngeal HNSCC [90]. However, HNSCC radiation resistance is intensely regulated by intrinsic cell-signaling pathways and mutational landscape. TP53 mutations are significantly associated with shorter OS and tumor resistance to radiotherapy and chemotherapy, which makes p53 status a potentially useful molecular prognostic and predictive factor for clinicians. Likewise, overexpression of epidermal growth factor receptor (EGFR) highlighted higher rates of post-radiation locoregional failure, suggesting that EGFR contributes to radiation resistance in about $40-70 \%$ of the cases [91].

\section{Conclusions}

The efficacy and toxicity of radiotherapy is closely related to the immunological balance of the host: the composition of the intestinal microbiota, the presence of active infection, autoimmune diseases, concomitant or recent exposure to immunosuppressive drugs may reduce radiosensitivity and consequently the development of a robust abscopal response [92]. Additionally, immunonutrition could contribute to stimulate immune functions and antioxidant defense capacities of leukocytes in head and neck cancer patients, as evidenced by Talvas et al. [93].

In conclusion, there is still an important gap between clinical and preclinical experiences, nevertheless, we should "tailor" the abscopal effect on the patient as shown (Figure 2). It is initially necessary to identify the most radiosensitive and potentially immune-stimulable primary tumor and metastatic sites too, with particular attention to draining nodal stations; then the dose, the fractionation, and the right volume of irradiation must be analyzed, integrating radiation at low doses with high doses, preferring hRT schedules, remembering that parenchymal diseases respond differently to each other and compared to lymph node disease. Finally, the right radiotherapy-immunotherapy sequence should be established, possibly associating ICIs 5-10 days after starting radiotherapy. Optimal radioimmunotherapy combinations should be critically designed comparing the effects of associations with immunotherapy alone, as exemplified in the IMPORTANCE 
trial (NCT03386357) for the treatment of recurrent or metastatic HNSCC. Finally, stronger conclusions should only be addressed with clinical trials comparing sparing lymph node RT versus draining node irradiation. This will make it easier to "tailor" the abscopal effect and dramatically improve the overall survival and quality of life of HNSCC patients.

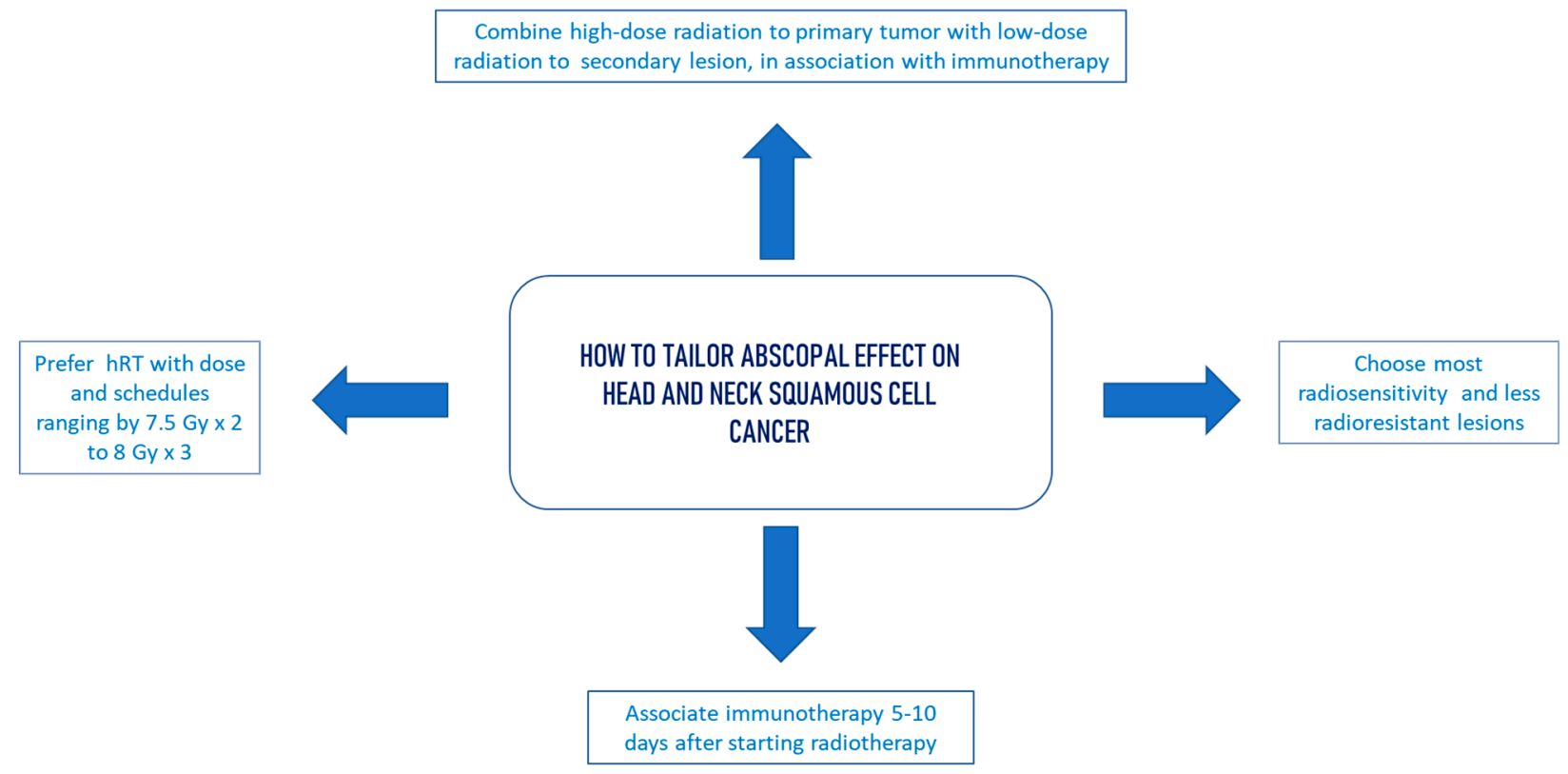

Figure 2. Clinical approaches to reproducing the abscopal effect in head and neck cancer.

Author Contributions: All authors have equally contributed to the published version of the manuscript. All authors have read and agreed to the published version of the manuscript.

Funding: This research received no external funding.

Institutional Review Board Statement: Not applicable.

Informed Consent Statement: Not applicable.

Data Availability Statement: Not applicable.

Conflicts of Interest: None of the authors have any conflicts of interest in association with this manuscript.

\section{References}

1. Siegel, R.L.; Miller, K.D.; Jemal, A. Cancer statistics, 2020. Cancer J Clin. 2020, 70, 7-30.

2. Bernier, J.; Domenge, C.; Ozsahin, M.; Matuszewska, K.; Lefèbvre, J.-L.; Greiner, R.H.; Giralt, J.; Maingon, P.; Rolland, F.; Bolla, M.; et al. Postop-erative irradiation with or without concomitant chemotherapy for locally advanced head and neck cancer. $N$. Engl. J. Med. 2004, 350, 1945-1952. [CrossRef] [PubMed]

3. Bonner, J.A.; Harari, P.M.; Giralt, J.; Cohen, R.B.; Jones, C.U.; Sur, R.K.; Raben, D.; Baselga, J.; A Spencer, S.; Zhu, J.; et al. Radiotherapy plus cetuximab for locoregionally advanced head and neck cancer: 5-year survival data from a phase 3 randomised trial, and relation between cetuximab-induced rash and survival. Lancet Oncol. 2010, 11, 21-28. [CrossRef]

4. Vermorken, J.B.; Mesia, R.; Rivera, F.; Remenar, E.; Kawecki, A.; Rottey, S.; Erfan, J.; Zabolotnyy, D.; Kienzer, H.-R.; Cupissol, D.; et al. Platinum-Based Chemotherapy plus Cetuximab in Head and Neck Cancer. N. Engl. J. Med. 2008, 359, $1116-1127$. [CrossRef] [PubMed]

5. Siddiqui, F.; Patel, M.; Khan, M.; McLean, S.; Dragovic, J.; Jin, J.-Y.; Movsas, B.; Ryu, S. Stereotactic Body Radiation Therapy for Primary, Recurrent, and Metastatic Tumors in the Head-and-Neck Region. Int. J. Radiat. Oncol. 2009, 74, 1047-1053. [CrossRef]

6. Orth, M.; Lauber, K.; Niyazi, M.; Friedl, A.; Li, M.; Maihöfer, C.; Schüttrumpf, L.; Ernst, A.; Niemöller, O.M.; Belka, C. Current concepts in clinical radiation oncology. Radiat. Environ. Biophys. 2014, 53, 1-29. [CrossRef]

7. Mole, R.H. Whole Body Irradiation-Radiobiology or Medicine? Br. J. Radiol. 1953, 26, 234-241. [CrossRef]

8. Ashrafizadeh, M.; Farhood, B.; Musa, A.E.; Taeb, S.; Rezaeyan, A.; Najafi, M. Abscopal effect in radioimmunotherapy. Int. Immunopharmacol. 2020, 85, 106663. [CrossRef] 
9. Marciscano, A.E.; Haimovitz-Friedman, A.; Lee, P.; Tran, P.T.; Tomé, W.A.; Guha, C.; Kong, F.-M.; Sahgal, A.; El Naqa, I.; Rimner, A.; et al. Immunomodulatory Effects of Stereotactic Body Radiation Therapy: Preclinical Insights and Clinical Opportunities. Int. J. Radiat. Oncol. Biol. Phys. 2021, 110, 35-52. [CrossRef]

10. Ward, J. DNA Damage Produced by Ionizing Radiation in Mammalian Cells: Identities, Mechanisms of Formation, and Reparability. Prog. Nucleic Acid Res. Mol. Biol. 1988, 35, 95-125. [CrossRef]

11. Barker, H.E.; Paget, J.T.; Khan, A.A.; Harrington, K.J. The tumour microenvironment after radiotherapy: Mechanisms of resistance and recurrence. Nat. Rev. Cancer 2015, 15, 409-425. [CrossRef]

12. De Leve, S.; Wirsdorfer, F.; Jendrossek, V. Targeting the immunomodulatory CD73/adenosine system to improve the therapeutic gain of radiotherapy. Front. Immunol. 2019, 10, 698. [PubMed]

13. Vanpouille-Box, C.; Diamond, J.M.; Pilones, K.A.; Zavadil, J.; Babb, J.S.; Formenti, S.C.; Barcellos-Hoff, M.H.; Demaria, S. TGFbeta is a master regulator of radiation therapy-induced antitumor immunity. Cancer Res. 2015, 75, 2232-2242. [CrossRef]

14. Wennerberg, E.; Lhuillier, C.; Vanpouille-Box, C.; Pilones, K.A.; García-Martínez, E.; Rudqvist, N.P.; Formenti, S.C.; Demaria, S. Barriers to radiation-induced in situ tumor vaccination. Front. Immunol. 2017, 8, 229. [PubMed]

15. Darragh, L.B.; Oweida, A.J.; Karam, S.D. Overcoming resistance to combination ra-diation-immunotherapy: A focus on contributing pathways within the tumor microenvironment. Front. Immunol. 2018, 9, 3154.

16. Mantovani, A.; Bottazzi, B.; Colotta, F.; Sozzani, S.; Ruco, L. The origin and function of tumor-associated macrophages. Immunol. Today 1992, 13, 265-270. [CrossRef]

17. Mantovani, A.; Sozzani, S.; Locati, M.; Allavena, P.; Sica, A. Macrophage polarization: Tumor-associated macrophages as a paradigm for polarized M2 mononuclear phagocytes. Trends Immunol. 2002, 23, 549-555. [CrossRef]

18. Butte, M.J.; Keir, M.E.; Phamduy, T.B.; Sharpe, A.H.; Freeman, G.J. Freeman Programmed Death-1 Ligand 1 Inter-acts Specifically with the B7-1 Costimulatory Molecule to Inhibit T Cell Responses. Immunity 2007, 27, 111-122. [CrossRef]

19. Matsuoka, Y.; Nakayama, H.; Yoshida, R.; Hirosue, A.; Nagata, M.; Tanaka, T.; Kawahara, K.; Sakata, J.; Arita, H.; Nakashima, H.; et al. Il-6 controls resistance to radiation by suppressing oxidative stress via thenrf2-antioxidant pathway in oral squamous cell carcinoma. Br. J. Cancer 2016, 115, 1234-1244. [CrossRef]

20. Ding, Q.; Lu, P.; Xia, Y.; Ding, S.; Fan, Y.; Li, X.; Han, P.; Liu, J.; Tian, D.; Liu, M. CXCL9: Evidence and contradictions for its role in tumor progression. Cancer Med. 2016, 5, 3246-3259. [CrossRef]

21. Wendel, M.; Galani, I.E.; Suri-Payer, E.; Cerwenka, A. Natural killer cell accumula-tion in tumors is dependent on IFN-gamma and CXCR3 ligands. Cancer Res. 2008, 68, 8437-8445. [CrossRef]

22. Mikucki, M.E.; Fisher, D.T.; Matsuzaki, J.; Skitzki, J.J.; Gaulin, N.B.; Muhitch, J.B.; Ku, A.W.; Frelinger, J.G.; Odunsi, K.; Gajewski, T.F.; et al. Non-redundant requirement for CXCR3 signalling during tumoricidal T-cell trafficking across tumour vascular checkpoints. Nat. Commun. 2015, 6, 7458. [CrossRef]

23. Galluzzi, L.; Buqué, A.; Kepp, O.; Zitvogel, L.; Kroemer, G. Immunogenic cell death in cancer and infectious disease. Nat. Rev. Immunol. 2017, 17, 97-111. [CrossRef] [PubMed]

24. Kepp, O.; Senovilla, L.; Vitale, I.; Vacchelli, E.; Adjemian, S.; Agostinis, P.; Apetoh, L.; Aranda, F.; Barnaba, V.; Bloy, N.; et al. Consensus guidelines for the detection of immunogenic cell death. OncoImmunology 2014, 3, e955691. [CrossRef]

25. Galluzzi, L.; Yamazaki, T.; Kroemer, G. Linking cellular stress responses to systemic homeostasis. Nat. Rev. Mol. Cell Biol. 2018, 19, 731-745. [CrossRef] [PubMed]

26. Mariathasan, S.; Turley, S.J.; Nickles, D.; Castiglioni, A.; Yuen, K.; Wang, Y.; Kadel, E.E., III; Koeppen, H.; Astarita, J.L.; Cubas, R.; et al. TGFbeta attenuates tumour response to PD-L1 blockade by contributing to exclusion of T cells. Nature 2018, 554, 544-548. [CrossRef]

27. Wang, J.; Zheng, H.; Sung, C.C.; Richter, K.K.; Hauer-Jensen, M. Cellular sources of transforming growth factor-beta isoforms in early and chronic radiation enteropathy. Am. J. Pathol. 1998, 153, 1531-1540. [CrossRef]

28. Vigneron, N. Human tumor antigens and cancer immunotherapy. Biomed. Res. Int. 2015, 2015, 948501. [CrossRef] [PubMed]

29. Bhalla, N.; Brooker, R.; Brada, M. Combining immunotherapy and radiotherapy in lung cancer. J. Thorac. Dis. 2018, 10, S1447-S1460. [CrossRef]

30. Wang, H.; Hu, S.; Chen, X.; Shi, H.; Chen, C.; Sun, L.; Chen, Z.J. cGAS is essential for the antitumor effect of immune checkpoint blockade. Proc. Natl. Acad. Sci. USA 2017, 114, 1637-1642. [CrossRef]

31. Burnette, B.C.; Liang, H.; Lee, Y.; Chlewicki, L.; Khodarev, N.N.; Weichselbaum, R.R.; Fu, Y.-X.; Auh, S.L. The Efficacy of Radiotherapy Relies upon Induction of Type I Interferon-Dependent Innate and Adaptive Immunity. Cancer Res. 2011, 71, 2488-2496. [CrossRef]

32. Vanpouille-Box, C.; Formenti, S.C.; DeMaria, S. TREX1 dictates the immune fate of irradiated cancer cells. OncoImmunology 2017, 6, e1339857. [CrossRef] [PubMed]

33. Vanpouille-Box, C.; Alard, A.; Aryankalayil, M.J.; Sarfraz, Y.; Diamond, J.M.; Schneider, R.J.; Inghirami, G.; Coleman, C.N.; Formenti, S.C.; DeMaria, S. DNA exonuclease Trex1 regulates radiotherapy-induced tumour immunogenicity. Nat. Commun. 2017, 8, 15618. [CrossRef]

34. Demaria, S.; Ng, B.; Devitt, M.L.; Babb, J.S.; Kawashima, N.; Liebes, L.; Formenti, S.C. Ionizing radiation inhibition of distant untreated tumors (abscopal effect) is immune me-diated. Int. J. Radiat. Oncol. Biol. Phys. 2004, 58, 862-870. [CrossRef] [PubMed]

35. Deng, L.; Liang, H.; Burnette, B.; Weicheslbaum, R.R.; Fu, Y.X. Radiation and an- ti-PD-L1 antibody combinatorial therapy induces T cell-mediated depletion of myeloid-derived suppressor cells and tumor regression. Oncoimmunology 2014, 3, e28499. [CrossRef] 
36. Dong, H.; Strome, S.E.; Salomao, D.R.; Tamura, H.; Hirano, F.; Flies, D.B.; Roche, P.C.; Lu, J.; Zhu, G.; Tamada, K.; et al. Tumor-associated B7-H1 promotes T-cell apoptosis: A potential mechanism of immune evasion. Nat. Med. 2002, 8, 793-800. [CrossRef]

37. Demaria, S.; Kawashima, N.; Yang, A.M.; Devitt, M.L.; Babb, J.S.; Allison, J.P.; Formenti, S.C. Immune-mediated inhibition of metastases after treatment with local radiation and CTLA-4 blockade in a mouse model of breast cancer. Clin. Cancer Res. 2005, 11 2 Pt 1, 728-734.

38. Verbrugge, I.; Hagekyriakou, J.; Sharp, L.L.; Galli, M.; West, A.; McLaughlin, N.M.; Duret, H.; Yagita, H.; Johnstone, R.W.; Smyth, M.J.; et al. Radiotherapy increases the permissiveness of established mammary tumors to rejection by immunomodulatory antibodies. Cancer Res. 2012, 72, 3163-3174. [CrossRef] [PubMed]

39. Sharabi, A.B.; Nirschl, C.J.; Kochel, C.M.; Nirschl, T.R.; Francica, B.J.; Velarde, E.; Deweese, T.L.; Drake, C.G. Stereotactic radiation therapy augments antigen-specific PD-1-mediated antitumor immune responses via cross-presentation of tumor antigen. Cancer Immunol. Res. 2015, 3, 345-355. [CrossRef] [PubMed]

40. Sato, H.; Niimi, A.; Yasuhara, T.; Permata, T.B.M.; Hagiwara, Y.; Isono, M.; Nuryadi, E.; Sekine, R.; Oike, T.; Kakoti, S.; et al. DNA double-strand break repair pathway regulates PD-L1 expression in cancer cells. Nat. Commun. 2017, 8, 1751. [CrossRef]

41. Liu, Y.; Dong, Y.; Kong, L.; Shi, F.; Zhu, H.; Yu, J. Abscopal effect of radiotherapy combined with immune checkpoint inhibitors. J. Hematol. Oncol. 2018, 11, 104. [CrossRef]

42. Latchman, Y.E.; Wood, C.R.; Chernova, T.; Chaudhary, D.; Borde, M.; Chernova, I.; Iwai, Y.; Long, A.J.; A Brown, J.; Nunes, R.; et al. PD-L2 is a second ligand for PD-1 and inhibits T cell activation. Nat. Immunol. 2001, 2, 261-268. [CrossRef] [PubMed]

43. Callahan, M.K.; Wolchok, J.D. At the Bedside: CTLA-4- and PD-1-blocking antibodies in cancer immunotherapy. J. Leukoc. Biol. 2013, 94, 41-53. [CrossRef]

44. Twyman-Saint Victor, C.; Rech, A.J.; Maity, A.; Rengan, R.; Pauken, K.E.; Stelekati, E.; Benci, J.L.; Xu, B.; Dada, H.; Odorizzi, P.M.; et al. Radiation and dual checkpoint blockade activate non-redundant immune mechanisms in cancer. Nature 2015, 520, 373-377. [CrossRef] [PubMed]

45. Dovedi, S.J.; Adlard, A.L.; Lipowska-Bhalla, G.; McKenna, C.; Jones, S.; Cheadle, E.J.; Stratford, I.J.; Poon, E.; Morrow, M.; Stewart, R.; et al. Acquired resistance to fractionated radio-therapy can be overcome by concurrent PD-L1 blockade. Cancer Res. 2014, 74 5458-5468. [PubMed]

46. Barber, D.L.; Wherry, E.J.; Masopust, D.; Zhu, B.; Allison, J.; Sharpe, A.H.; Freeman, G.J.; Ahmed, R. Restoring function in exhausted CD8 T cells during chronic viral infection. Nat. Cell Biol. 2005, 439, 682-687. [CrossRef] [PubMed]

47. Gong, X.; Li, X.; Jiang, T.; Xie, H.; Zhu, Z.; Zhou, F.; Zhou, C. Combined Radiotherapy and Anti-PD-L1 Antibody Synergistically En-hances Antitumor Effect in Non-Small Cell Lung Cancer. J. Thorac. Oncol. 2017, 12, 1085-1097.

48. Hettich, M.; Lahoti, J.; Prasad, S.; Niedermann, G. Checkpoint Antibodies but not T Cell-Recruiting Diabodies Effectively Synergize with TIL-Inducing $\gamma$-Irradiation. Cancer Res. 2016, 76, 4673-4683. [CrossRef]

49. Frey, B.; Rückert, M.; Weber, J.; Mayr, X.; Derer, A.; Lotter, M.; Bert, C.; Rödel, F.; Fietkau, R.; Gaipl, U.S. Hypofractionated Irradiation Has Immune Stimulatory Potential and Induces a Timely Restricted Infiltration of Immune Cells in Colon Cancer Tumors. Front. Immunol. 2017, 8, 231. [CrossRef]

50. Nakamura, N.; Kusunoki, Y.; Akiyama, M. Radiosensitivity of CD4 or CD8 positive human T-lymphocytes by an in vitro colony formation assay. Radiat Res. 1990, 123, 224-227. [CrossRef]

51. Heylmann, D.; Rödel, F.; Kindler, T.; Kaina, B. Radiation sensitivity of human and murine peripheral blood lymphocytes, stem and progenitor cells. Biochim. Biophys. Acta. 2014, 1846, 121-129. [CrossRef]

52. Zhang, X.; Niedermann, G. Abscopal Effects with Hypofractionated Schedules Extending Into the Effector Phase of the TumorSpecific T-Cell Response. Int. J. Radiat. Oncol. 2018, 101, 63-73. [CrossRef]

53. Morisada, M.; Clavijo, P.E.; Moore, E.; Sun, L.; Chamberlin, M.; Van Waes, C.; Hodge, J.W.; Mitchell, J.B.; Friedman, J.; Allen, C.T. PD-1 blockade reverses adaptive immune resistance induced by high-dose hypofractionated but not low-dose daily fractionated radiation. OncoImmunology 2017, 7, e1395996. [CrossRef] [PubMed]

54. Schaue, D.; Ratikan, J.A.; Iwamoto, K.S.; McBride, W.H. Maximizing Tumor Immunity With Fractionated Radiation. Int. J. Radiat. Oncol. 2012, 83, 1306-1310. [CrossRef] [PubMed]

55. Dewan, M.Z.; Galloway, A.E.; Kawashima, N.; Dewyngaert, J.K.; Babb, J.S.; Formenti, S.C.; Demaria, S. Fractionated but not single-dose radiotherapy induces an immune-mediated abscopal effect when combined with anti-CTLA-4 antibody. Clin. Cancer Res. 2009, 15, 5379-5388. [CrossRef]

56. Brooks, E.D.; Chang, J.Y. Time to abandon single-site irradiation for inducing abscopal effects. Nat. Rev. Clin. Oncol. 2019, 16, 123-135. [CrossRef]

57. Demaria, S.; Golden, E.B.; Formenti, S.C. Role of Local Radiation Therapy in Cancer Immunotherapy. JAMA Oncol. 2015, 1, 1325-1332. [CrossRef] [PubMed]

58. Klug, F.; Prakash, H.; Huber, P.E.; Seibel, T.; Bender, N.; Halama, N.; Pfirschke, C.; Voss, R.H.; Timke, C.; Umansky, L.; et al. Low-Dose Irradiation Programs Macrophage Differentiation to an iNOS+/M1 Phenotype that Orchestrates Effective T Cell Immunotherapy. Cancer Cell 2013, 24, 589-602. [CrossRef]

59. De Palma, M.; Coukos, G.; Hanahan, D. A new twist on radiation oncology: Low-dose irradiation elicits immunostimulatory macrophages that unlock barriers to tumor immunotherapy. Cancer Cell 2013, 24, 559-561. [CrossRef] 
60. Yin, L.; Xue, J.; Li, R.; Zhou, L.; Deng, L.; Chen, L.; Zhang, Y.; Li, Y.; Zhang, X.; Xiu, W.; et al. Effect of Low-Dose Radiation Therapy on Abscopal Responses to Hypofractionated Radiation Therapy and Anti-PD1 in Mice and Patients With Non-Small Cell Lung Cancer. Int. J. Radiat. Oncol. 2020, 108, 212-224. [CrossRef]

61. Menon, H.; Chen, D.; Ramapriyan, R.; Verma, V.; Barsoumian, H.B.; Cushman, T.R.; Younes, A.; Cortez, M.A.; Erasmus, J.J.; De Groot, P.; et al. Influence of low-dose radiation on abscopal responses in patients receiving high-dose radiation and immunotherapy. J. Immunother. Cancer 2019, 7, 237. [CrossRef]

62. Golden, E.B.; Chhabra, A.; Chachoua, A.; Adams, S.; Donach, M.; Fenton-Kerimian, M.; Friedman, K.; Ponzo, F.; Babb, J.S.; Goldberg, P.J.; et al. Local radiotherapy and granulo-cyte-macrophage colony-stimulating factor to generate abscopal responses in patients with metastatic solid tumours: A proof-of-principle trial. Lancet Oncol. 2015, 16, 795-803.

63. Trommer, M.; Yeo, S.Y.; Persigehl, T.; Bunck, A.; Grüll, H.; Schlaak, M.; Theurich, S.; Von Bergwelt-Baildon, M.; Morgenthaler, J.; Herter, J.M.; et al. Abscopal Effects in Radio-Immunotherapy—Response Analysis of Metastatic Cancer Patients With Progressive Disease Under Anti-PD-1 Immune Checkpoint Inhibition. Front. Pharmacol. 2019, 10, 511. [CrossRef]

64. Theelen, W.S.M.E.; Peulen, H.M.U.; Lalezari, F.; Van Der Noort, V.; De Vries, J.F.; Aerts, J.G.J.V.; Dumoulin, D.W.; Bahce, I.; Niemeijer, A.-L.N.; De Langen, A.J.; et al. Effect of Pembrolizumab After Stereotactic Body Radiotherapy vs. Pembrolizumab Alone on Tumor Response in Patients With Advanced Non-Small Cell Lung Cancer: Results of the PEMBRO-RT Phase 2 Randomized Clinical Trial. JAMA Oncol. 2019, 5, 1276-1282. [CrossRef] [PubMed]

65. Garon, E.B.; Rizvi, N.A.; Hui, R.; Leighl, N.; Balmanoukian, A.S.; Eder, J.P.; Patnaik, A.; Aggarwal, C.; Gubens, M.; Horn, L.; et al. Pembrolizumab for the Treatment of Non-Small-Cell Lung Cancer. N. Engl. J. Med. 2015, 372, 2018-2028. [CrossRef] [PubMed]

66. Stevens, C.M.; Huang, S.H.; Fung, S.; Bayley, A.J.; Cho, J.B.; Cummings, B.J.; Dawson, L.; Hope, A.J.; Kim, J.J.; O'Sullivan, B.; et al. Retrospective Study of Palliative Radiotherapy in Newly Diagnosed Head and Neck Carcinoma. Int. J. Radiat. Oncol. 2011, 81, 958-963. [CrossRef]

67. Corry, J.; Peters, L.J.; D’Costa, I.; Milner, A.D.; Fawns, H.; Rischin, D.; Porceddu, S. The ‘QUAD SHOT'-a phase II study of palliative radio-therapy for incurable head and neck cancer. Radiother. Oncol. 2005, 77, 137-142. [CrossRef] [PubMed]

68. Agarwal, J.P.; Nemade, B.; Murthy, V.; Ghosh-Laskar, S.; Budrukkar, A.; Gupta, T.; D’Cruz, A.; Pai, P.; Chaturvedi, P.; Dinshaw, K. Hypofractionated, palliative radiotherapy for advanced head and neck cancer. Radiother. Oncol. 2008, 89, 51-56. [CrossRef] [PubMed]

69. Cancer Genome Atlas Network. Comprehensive genomic characterization of head and neck squamous cell carcinomas. Nature 2015, 517, 576-582. [CrossRef]

70. Cancer Genome Atlas Network. Genomic classification of cutaneous melanoma. Cell 2015, 161, 1681-1696.

71. Coelho, M.A.; de Carné Trécesson, S.; Rana, S.; Zecchin, D.; Moore, C.; Molina-Arcas, M.; East, P.; Spencer-Dene, B.; Nye, E.; Barnouin, K.; et al. Oncogenic RAS signaling promotes tumor immunoresistance by stabilizing PD-L1 mRNA. Immunity 2017, 47, 1083-1099.e6. [CrossRef] [PubMed]

72. Ellerin, B.; Demandante, C.; Martins, J. Pure abscopal effect of radiotherapy in a salivary gland carcinoma: Case report, literature review, and a search for new approaches. Cancer/Radiothérapie 2020, 24, 226-246. [CrossRef]

73. Forner, D.; Horwich, P.; Trites, J.; Hollenhorst, H.; Bullock, M.; Lamond, N. The Abscopal Effect in Head-and-Neck Squamous Cell Carcinoma Treated with Radiotherapy and Nivolumab: A Case Report and Literature Review. Curr. Oncol. 2020, 27, 330-335. [CrossRef] [PubMed]

74. Mazzaschi, G.; Tommasi, C.; Pietri, E.; Corcione, L.; De Giorgi, A.; Bini, P.; Bui, S. Abscopal effect as part of treatment of oligometastatic head and neck cancer: A case report. Clin. Case Rep. 2021, 9, 1334-1338. [CrossRef]

75. Choi, J.S.; Sansoni, E.R.; Lovin, B.D.; Lindquist, N.R.; Phan, J.; Mayo, L.L.; Ferrarotto, R.; Su, S. Abscopal Effect Following Immunotherapy and Combined Stereotactic Body Radiation Therapy in Recurrent Metastatic Head and Neck Squamous Cell Carcinoma: A Report of Two Cases and Literature Review. Ann. Otol. Rhinol. Laryngol. 2019, 129, 517-522. [CrossRef] [PubMed]

76. Shinde, A.; Novak, J.; Freeman, M.L.; Glaser, S.; Amini, A. Induction of the abscopal effect with immunotherapy and palliative ra-diation in metastatic head and neck squamous cell carcinoma: A case report and review of the literature. Cureus 2019, 11, e4201.

77. Gholami, S.; Nedaie, H.A.; Longo, F.; Ay, M.R.; Wright, S.; Meigooni, A.S. Is grid therapy useful for all tumors and every grid block design? J. Appl. Clin. Med. Phys. 2016, 17, 206-219. [CrossRef] [PubMed]

78. Bahig, H.; Aubin, F.; Stagg, J.; Gologan, O.; Ballivy, O.; Bissada, E.; Nguyen-Tan, F.; Soulières, D.; Guertin, L.; Filion, E.; et al. Phase I/II trial of durvalumab plus tremelimumab and ste-reotactic body radiotherapy for metastatic head and neck carcinoma. BMC Cancer 2019, 19, 68. [CrossRef]

79. Poleszczuk, J.T.; Luddy, K.; Prokopiou, S.; Robertson-Tessi, M.; Moros, E.; Fishman, M.; Djeu, J.Y.; Finkelstein, S.E.; Enderling, H. Abscopal Benefits of Localized Radiotherapy Depend on Activated T-cell Trafficking and Distribution between Metastatic Lesions. Cancer Res. 2016, 76, 1009-1018. [CrossRef]

80. Tang, C.; Liao, Z.; Gomez, D.; Levy, L.; Zhuang, Y.; Gebremichael, R.A.; Hong, D.S.; Komaki, R.; Welsh, J.W. Lymphopenia Association with Gross Tumor Volume and Lung V5 and Its Effects on Non-Small Cell Lung Cancer Patient Outcomes. Int. J. Radiat. Oncol. 2014, 89, 1084-1091. [CrossRef]

81. Chen, D.; Verma, V.; Patel, R.R.; Barsoumian, H.B.; Cortez, M.A.; Welsh, J.W. Absolute Lymphocyte Count Predicts Abscopal Responses and Outcomes in Patients Receiving Combined Immunotherapy and Radiation Therapy: Analysis of 3 Phase 1/2 Trials. Int. J. Radiat. Oncol. 2020, 108, 196-203. [CrossRef] 
82. Deutsch, E.; Chargari, C.; Galluzzi, L.; Kroemer, G. Optimising efficacy and reducing toxicity of anticancer radioimmunotherapy. Lancet Oncol. 2019, 20, e452-e463. [CrossRef]

83. Bentzen, S.M.; Harari, P.M.; Bernier, J. Exploitable mechanisms for combining drugs with radiation: Concepts, achievements and future directions. Nat. Clin. Pract. Oncol. 2007, 4, 172-180. [CrossRef] [PubMed]

84. Ma, Y.; Adjemian, S.; Mattarollo, S.; Yamazaki, T.; Aymeric, L.; Yang, H.; Catani, J.P.P.; Hannani, D.; Duret, H.; Steegh, K.; et al. Anticancer Chemotherapy-Induced Intratumoral Recruitment and Differentiation of Antigen-Presenting Cells. Immunity 2013, 38, 729-741. [CrossRef]

85. Chen, J.; Ou, D.; He, X.; Hu, C. Sparing level Ib lymph nodes by intensity-modulated radiotherapy in the treatment of nasopharyngeal carcinoma. Int. J. Clin. Oncol. 2014, 19, 998-1004. [PubMed]

86. Luke, J.J.; Lemons, J.M.; Karrison, T.G.; Pitroda, S.P.; Melotek, J.M.; Zha, Y.; Al-Hallaq, H.A.; Arina, A.; Khodarev, N.N.; Janisch, L.; et al. Safety and clinical activity of pembrolizumab and multisite stereotactic body radio-therapy in patients with advanced solid tumors. J. Clin. Oncol. 2018, 36, 1611-1618. [CrossRef]

87. Formenti, S.C.; Demaria, S. Understanding Responses to Stereotactic Body Radiotherapy and Pembrolizumab. J. Clin. Oncol. 2018, 36, 2661-2662. [CrossRef] [PubMed]

88. Michna, A.; Schötz, U.; Selmansberger, M.; Zitzelsberger, H.; Lauber, K.; Unger, K.; Hess, J. Transcriptomic analyses of the radiation response in head and neck squamous cell carcinoma subclones with different radiation sensitivity: Time-course gene expression profiles and gene association networks. Radiat. Oncol. 2016, 11, 94. [CrossRef]

89. Strom, T.; Harrison, L.B.; Giuliano, A.R.; Schell, M.J.; Eschrich, S.A.; Berglund, A.; Fulp, W.; Thapa, R.; Coppola, D.; Kim, S.; et al. Tumour radiosensitivity is associated with immune activation in solid tumours. Eur. J. Cancer 2017, 84, 304-314. [CrossRef]

90. Reynders, K.; Illidge, T.; Siva, S.; Chang, J.Y.; De Ruysscher, D. The abscopal effect of local radiotherapy: Using immunotherapy to make a rare event clinically relevant. Cancer Treat. Rev. 2015, 41, 503-510. [CrossRef]

91. Zhou, G.; Liu, Z.; Myers, J.N. TP53Mutations in Head and Neck Squamous Cell Carcinoma and Their Impact on Disease Progression and Treatment Response. J. Cell. Biochem. 2016, 117, 2682-2692. [CrossRef] [PubMed]

92. Galluzzi, L.; Chan, T.A.; Kroemer, G.; Wolchok, J.D.; López-Soto, A. The hallmarks of successful anticancer immunotherapy. Sci. Transl. Med. 2018, 10, eaat7807. [CrossRef] [PubMed]

93. Talvas, J.; Garrait, G.; Goncalves-Mendes, N.; Rouanet, J.; Vergnaud-Gauduchon, J.; Kwiatkowski, F.; Bachmann, P.; Bouteloup, C.; Bienvenu, J.; Vasson, M.-P. Immunonutrition stimulates immune functions and antioxidant defense capacities of leukocytes in radiochemotherapy-treated head \& neck and esophageal cancer patients: A double-blind randomized clinical trial. Clin. Nutr. 2015, 34, 810-817. [CrossRef] [PubMed] 